\title{
Early detection of multidrug- and pre- extensively drug-resistant tuberculosis from smear-positive sputum by direct sequencing
}

\author{
Jun Chen ${ }^{1}$, Peng Peng ${ }^{2}$, Yixiang Du ${ }^{3}$ Yi Ren ${ }^{1}$, Lifeng Chen ${ }^{1}$, Youyi Rao ${ }^{1}$ and Weihua Wang ${ }^{2^{*}}$
}

\begin{abstract}
Background: Emergence of multidrug- and extensively drug-resistant tuberculosis (M/XDR-TB) is a major hurdle for TB control programs especially in developing countries like China. Resistance to fluoroquinolones is high among MDR-TB patients. Early diagnosis of MDR/pre-XDR-TB is essential for lowering transmission of drug-resistant TB and adjusting the treatment regimen.

Methods: Smear-positive sputum specimens $(n=186)$ were collected from Wuhan Institute for Tuberculosis Control. The DNA was extracted from the specimens and run through a Sanger sequencing assay to detect mutations associated with MDR/pre-XDR-TB including the rpoB core region for rifampicin (RIF) resistance; katG and inhA promoter for isoniazid (INH) resistance; and gyrA for fluoroquinolone (FQ) resistance. Sequencing data were compared to phenotypic Lowenstein-Jensen (L-J) proportion method drug susceptibility testing (DST) results for performance analysis.

Results: By comparing the mutation data with phenotypic results, the detection rates of MDR-TB and pre-XDR-TB were $84.31 \%$ (43/51) and 83.33\% (20/24), respectively. The sequencing assay illustrated good sensitivity for the detection of resistance to RIF (96.92\%), INH (86.89\%), FQ (77.50\%). The specificities of the assay were $98.35 \%$ for RIF, 99.20\% for $\mathrm{INH}$, and $97.26 \%$ for $\mathrm{FQ}$.

Conclusions: The sequencing assay is an efficient, accurate method for detection of MDR-TB and pre-XDR-TB from clinical smear-positive sputum specimens, should be considered as a supplemental method for obtaining early DST results before the availability of phenotypic DST results. This could be of benefit to early diagnosis, adjusting the treatment regimen and controlling transmission of drug-resistant TB.
\end{abstract}

Keywords: Mycobacterium tuberculosis, MDR-TB, Pre-XDR-TB, Rifampicin, Isoniazid, Fluoroquinolone

\section{Background}

The emergence and spread of multidrug-resistant tuberculosis (MDR-TB) and extensively drug-resistant tuberculosis (XDR-TB) has become a major public health threat worldwide. According to the recent report of World Health Organization (WHO), globally, an estimated $3.3 \%$ of new cases and $20 \%$ of previously treated cases have MDR-TB; these levels have remained virtually unchanged in recent

\footnotetext{
*Correspondence: drwang65@163.com

2Department of Internal Medicine, Wuhan Institute for Tuberculosis Control, Wuhan Pulmonary Hospital, Wuhan 430030, China

Full list of author information is available at the end of the article
}

years [1]. In 2014, there were an estimated 480,000 new cases of MDR-TB worldwide, and approximately 190,000 deaths from MDR-TB. Among patients with pulmonary TB who were notified in 2014, an estimated 300,000 had MDR-TB. More than half of these patients were in India, China and the Russian Federation. On average, an estimated $9.7 \%$ of people with MDR-TB have XDR-TB [1]. In 2007-08, a nationwide drug-resistance survey conducted in China showed that the proportion of MDR-TB in smearpositive pulmonary TB patients was $8.32 \%$. Of these, the proportion of MDR-TB in new patients and re-treated patients was 5.71 and $25.64 \%$, respectively [2]. 
Pre-XDR-TB denotes resistance to rifampicin and isoniazid, as well as to at least one fluoroquinolone $(\mathrm{FQ})$ or 1 second-line injectable drug: kanamycin, amikacin or capreomycin. FQs have been proven to be among the most effective second-line anti-mycobacterial drugs and are recommended for the treatment of MDR-TB [3]. When patients are infected with FQ-resistant MDR-TB strains, the treatment regimen needs to be adjusted and the prognosis is poor [4]. In China, among patients with MDR tuberculosis, $24.9 \%$ of those with new cases of tuberculosis and $27.5 \%$ of those with previously treated tuberculosis had resistance to ofloxacin [2]. In India, 29\% of patients with previously treated tuberculosis had resistance to ofloxacin [5]. The rates were as high as 60.6 and $78.3 \%$ in two hospital-based studies in Shandong province and Shanghai $[6,7]$. Therefore, effective and accurate diagnosis of these MDR-TB and pre-XDR-TB patients is urgently needed for choosing a reasonable regimen and preventing transmission.

Conventional TB diagnosis depends on culture growth of mycobacteria, which is very slow, time-consuming. Rapid molecular diagnostics, based on the detection of specific mutations that confer drug resistance, provide approaches to identify drug resistance in Mycobacterium tuberculosis (MTB). These technologies include the Hain MTBDRplus line probe assay, the genechip assay and the GeneXpert MTB/RIF assay [8-10]. However, these methods have some limitations, they are unable to distinguish silent mutations from mutations associated with drug resistance, and there has been little progress toward the broad application of these molecular diagnostics for the simultaneous detection mutations associated with resistance to the first-line and second-line antitubercular drugs [11-13]. In order to discover MDR-TB and pre-XDR-TB patients, we report an effective method which is able to detect MDR-TB and pre-XDR-TB from smear-positive sputum by direct sequencing.

\section{Methods}

Source of sputum specimens and the standard strain From February 2014 to January 2015, among 1233 suspected TB patients from Department of internal medicine in Wuhan Institute for Tuberculosis Control,Wuhan Pulmonary Hospital, 207 smear-positive sputum specimens were acquired, of which, 7 specimens were culturenegative, 5 specimens were contaminated, non-tubercular mycobacteria (NTM) were isolated from 4 specimens, 5 specimens were also excluded due to no amplification of four resistance-associated mutation genes, finally 186 sputum specimens were enrolled in this study. The 186 specimens came from 186 different patients: 91 initial treatment patients and 95 retreatment patients. The smear-positive sputum specimens were identified as MTB by detecting IS6110 positive by real-time PCR (Daan gene,
Guangzhou, China). Mycobacterium tuberculosis standard strain (H37Rv, ATCC27294) was purchased from the National Culture Collection (Beijing, China).

\section{Specimen processing and culture of Mycobacteria}

Every sputum specimen was decontaminated with a 2-4 fold volume of $4 \% \mathrm{NaOH}$, liquefied at room temperature for $20 \mathrm{~min}$. The processed specimen was inoculated on to Lowenstein-Jensen (L-J) based solid medium for isolation of Mycobacteria. The duration of incubation for L-J solid culture was 56 days.

\section{Genomic DNA extraction}

Transfer $1.0 \mathrm{ml}$ above liquefied sputum to a $1.5 \mathrm{ml}$ tube and centrifuge in a tabletop centrifuge at $6000 \mathrm{~g}$ for $15 \mathrm{~min}$ at room temperature. The supernatant was discarded carefully and the sediment was washed with $0.9 \% \mathrm{NaCl}$ solution and recentrifuged as before. The pellet was washed again. Next, 50ul lysis solution was added to the processed sediment, mixed well and incubated at $100{ }^{\circ} \mathrm{C}$ for $10 \mathrm{~min}$. The lysate was stored at $4-8{ }^{\circ} \mathrm{C}$ until use.

\section{Design of primers and PCR amplification}

Amplification and sequencing primers of $r p o B$ gene were described in a previous study [14]. The primers of katG, inhA promoter and gyrA genes were designed with Primer Premier software. Primer Pair Specificity was detected by Primer-BLAST [15]. Primers and amplicon sizes were presented in Table 1 . Amplification reaction were performed in a total volume of $30 \mu \mathrm{l}$ consisting of $15 \mu \mathrm{l} 2 \times$ PCR MIX (Fermentas), $3 \mu \mathrm{l} 2 \mu \mathrm{mol} / \mathrm{L}$ each primer, $2 \mu \mathrm{l}$ DNA lysate and $10 \mu \mathrm{lddH_{2 }}$ O. Thermo-cycling conditions were as follows: $95^{\circ} \mathrm{C}$ for 2 min followed by 40 cycles of $35 \mathrm{~s}$ at $95{ }^{\circ} \mathrm{C}, 30 \mathrm{~s}$ at $55{ }^{\circ} \mathrm{C}, 45 \mathrm{~s}$ at $72{ }^{\circ} \mathrm{C}$ and final elongation at $72{ }^{\circ} \mathrm{C}$ for $5 \mathrm{~min}$.

Sequencing of rpoB、katG、inhA promoter and gyrA genes PCR products were purified with UNIQ-10 column purification kit (Sangon, Shanghai, China) and then sequenced with an automatic DNA sequencer (Applied

Table 1 Primers for polymerase chain reaction amplification and sequencing

\begin{tabular}{lllc}
\hline Gene & Primer & Sequence & Size (bp) \\
\hline rpoB & Forward & CCACCCAGGACGTGGAGGCGATCACACCG & 329 \\
& Reverse & CGTITCATGAACCCGAACGGGTGAC & \\
katG & Forward & GGGGCTGATCTACGTGAACC & 363 \\
& Reverse & CTCTTCGTCAGCTCCCACTC & \\
inhA & Forward & ATGGAAGGCAGAAGCCGAGTA & 398 \\
promoter & Reverse & GACTGAACGGGATACGAATGG & \\
gyrA & Forward & CAGCGCAGCTACATCGACTA & 356 \\
& Reverse & CTCAGCATCTCCATCGCCAA & \\
\hline
\end{tabular}


Biosystems 3730xl DNA analyzer, USA). Mutations in $r p o B 、 k a t G$, inh $A$ promoter and gyrA genes were identified using BLASTn (https://blast.ncbi.nlm.nih.gov/blast.cgi) (version number: BLAST2.2.31) by comparison with Mycobacterium tuberculosis wild-type strain $\mathrm{H} 37 \mathrm{Rv}$ sequence. The mutations were compared with the TB Drug Resistance Mutation Database (https://tbdreamdb.ki.se/Info/) [16]. Sequences matching mutations previously associated with resistance were considered genotypically resistant, whereas wild-type sequences were considered genotypically susceptible, and those not matching resistance-associated mutations or wild-type sequences were considered genotypically indeterminate for the given gene regions [17].

\section{DST-drug susceptibility tests of Mycobacterium tuberculosis by L-J proportion method}

Cultures obtained on L-J medium were collected and tested susceptibility for rifampicin, isoniazid and ofloxacin. DST was performed by L-J proportion method. The critical drug concentrations were $40 \mu \mathrm{g} / \mathrm{ml}$ for rifampicin, $0.2 \mu \mathrm{g} / \mathrm{ml}$ for isoniazid and $2 \mu \mathrm{g} / \mathrm{ml}$ for ofloxacin. The standard strain $\mathrm{H} 37 \mathrm{Rv}$ was used as control. External quality assurance on DST by proficiency testing was conducted regularly (once a year) by the national reference laboratory of China.

\section{Statistical analysis}

SPSS 22.0 software (SPSS Inc., Chicago, IL, USA) was used for the statistical analysis. The sensitivity and specificity were calculated for sequencing results versus L-J proportion method, which was considered as the gold standard of DST.

\section{Results}

\section{Detection of MDR-TB and pre-XDR-TB by directing sequencing}

Among the 186 clinical isolates, no mixed culture was isolated, 105 isolates were susceptible to all of three drugs: RIF, INH and OFX. 51 isolates were MDR-TB strains, of which 24 isolates were pre-XDR-TB strains. The detection rates of MDR-TB and pre-XDR-TB by direct sequencing were $84.31 \%$ (43/51) and $83.33 \%$ (20/24), respectively.

\section{Sequencing results for the detection of gene mutations}

The mutations of the 186 smear-positive sputum specimens in rpoB, katG, inhA promoter and gyrA genes were shown in Table 2. Of the 186 smear-positive sputum specimens, the sequencing identified 13 types of mutations in rifampicin resistance-determining region (RRDR) of the $r p o B$ gene. The mutation rates of codon 531 and 526 were $67.69 \%(44 / 65)$ and $16.92 \%(11 / 65)$, respectively. One specimen had double mutation, and 2 specimens had base deletion. There were 2 types of mutations in $k a t G$ gene, which were in codon 315 . There were 4 types of mutations in inh $A$ promoter, $\mathrm{C}(-15) \rightarrow \mathrm{T}$ mutation $(10 / 14)$ was predominant. Among 54 specimens related to INH resistance, $75.93 \%$ (41/54) of the specimens had only kat $G$ gene mutation, $16.67 \%$ (9/54) had only inhA promoter mutation, $7.41 \%(4 / 54)$ had katG gene and inhA promoter mutations. There were 7 types of mutations in $g y r A$ gene. The mutation rates of codon 94 and 90 were $68.57 \%(24 / 35)$ and $20.00 \%(7 / 35)$, respectively. Three heteroresistant specimens were detected by Sanger sequencing plots, 2 with the katG S315 T mutation, 1 with the $r p o B$ S531 L mutation. All 3 specimens came from retreatment patients.

\section{The performance of direct sequencing for detection of MTB resistance}

Compared with L-J proportion method, direct sequencing showed higher sensitivities in RIF and INH than that in OFX. Specificities were very high in three drugs. The performance of direct sequencing for detection of MTB resistance was summarized in Table 3.

\section{Discussion}

Early diagnosis of MDR/pre-XDR-TB is crucially important for both working out a rational regimen and preventing the transmission of them. In this study, the drug-resistant loci of rpoB, $k a t G$, inh $A$ promoter and gyr $A$ genes were amplified and sequenced to detect mutations from smear-positive sputum. The entire procedure, from extracting DNA to reporting results, can be accomplished within 3 days, but the traditional culture method and DST needs 1 to 3 months. This shortened the turnaround time of DST. Direct sequencing in our study was able to detect not only MDR-TB, but also preXDR-TB, However, GeneXpert MTB/RIF assay and Hain MTBDRplus can only detect MDR-TB, not pre-XDR-TB. Zakham $\mathrm{F}$ et al. [18] also detected only MDR-TB by direct sequencing. Although pyrosequencing can be used to detect XDR-TB, fragments for pyrosequencing are short and more primer pairs are needed for amplifying long fragments, such as rpoB gene [17], at the same time, pyrosequencing applies to the sputum specimens of $1+$ or $2+$ acid-fast staining, the nested PCR might be essential [19]. Whole genome sequencing provides more information of resistance and helps explore new mechnisms of drug resistance, but this method is expensive and mainly used to sequence MTB strains [20].

Our results showed that the detection rates of MDR$\mathrm{TB}$ and pre-XDR-TB were $84.31 \%(43 / 51)$ and $83.33 \%$ (20/24), respectively. It was similar to MTBDRplus assay $[8,14]$. The detection rate $(84.31 \%)$ of MDR-TB was slightly lower that reported in previous study from Shanghai (88\%) [21]. It was possible that the mutations in kat $G$ and inhA promoter of 8 MDR-TB specimens were not detected by direct sequencing in our study. This indicated the complexity of INH resistance, and 
Table 2 Mutation distribution of rpoB, katG, inhA promoter and gyrA genes in the smear-positive sputum specimens

\begin{tabular}{|c|c|c|c|c|c|}
\hline Drugs & Genes & Nucleotide change & Amino acid change & Number(\%) & Number of phenotypically resistant strains \\
\hline \multirow[t]{13}{*}{ rifampicin } & \multirow[t]{13}{*}{$r p o B^{a}$} & $G(1546) \rightarrow T$ & $\operatorname{Asp}(516) \rightarrow \mathrm{Tyr}$ & $2(1.59)$ & 1 \\
\hline & & $\mathrm{A}(1547) \rightarrow \mathrm{T}$ & $\operatorname{Asp}(516) \rightarrow$ Val & $1(1.59)$ & 1 \\
\hline & & $\mathrm{A}(1547) \rightarrow \mathrm{T} ; \mathrm{A}(1552) \rightarrow \mathrm{G}^{\mathrm{b}}$ & $\begin{array}{l}\text { Asp (516) } \rightarrow \text { Val; } \\
\text { Asn(518) } \rightarrow \text { Asp }\end{array}$ & $1(1.59)$ & 1 \\
\hline & & AGA(1550-1552)deletion ${ }^{\mathrm{b}}$ & Frame shift & $1(1.59)$ & 1 \\
\hline & & $C(1576) \rightarrow T$ & $\operatorname{His}(526) \rightarrow \mathrm{Tyr}$ & $2(2.18)$ & 2 \\
\hline & & $C(1576) \rightarrow A$ & $\mathrm{His}(526) \rightarrow \mathrm{Asn}$ & $2(2.18)$ & 1 \\
\hline & & $C(1576) \rightarrow G$ & $\mathrm{His}(526) \rightarrow \mathrm{Asp}$ & $1(1.59)$ & 1 \\
\hline & & $\mathrm{A}(1577) \rightarrow \mathrm{T}$ & His(526) $\rightarrow$ Leu & $4(6.35)$ & 4 \\
\hline & & $A(1577) \rightarrow G$ & $\mathrm{His}(526) \rightarrow \operatorname{Arg}$ & $1(1.59)$ & 1 \\
\hline & & $A(1577) \rightarrow C$ & $\mathrm{His}(526) \rightarrow$ Pro & $1(1.59)$ & 1 \\
\hline & & $C(1592) \rightarrow T$ & $\operatorname{Ser}(531) \rightarrow$ Leu & $44(68.25)$ & 44 \\
\hline & & $\mathrm{T}(1598) \rightarrow C$ & Leu(533) $\rightarrow$ Pro & $4(6.35)$ & 4 \\
\hline & & C(1542) $\rightarrow$ T;ATGGAC(1543-1548)deletion ${ }^{\text {b }}$ & Frame shift & $1(1.59)$ & 1 \\
\hline \multirow[t]{6}{*}{ isoniazid } & \multirow[t]{2}{*}{ katG } & $\mathrm{G}(944) \rightarrow \mathrm{C}$ & $\operatorname{Ser}(315) \rightarrow \operatorname{Thr}$ & 40(95.24) & 40 \\
\hline & & $\mathrm{G}(944) \rightarrow \mathrm{A}$ & $\operatorname{Ser}(315) \rightarrow$ Asn & $2(4.76)$ & 2 \\
\hline & \multirow[t]{4}{*}{ inhA promoter } & $\mathrm{T}(-8) \rightarrow C$ & & $1(7.69)$ & 1 \\
\hline & & $C(-15) \rightarrow T$ & & $10(76.92)$ & 9 \\
\hline & & $\mathrm{G}(-17) \rightarrow \mathrm{T}$ & & $1(7.69)$ & 1 \\
\hline & & $C(-34) \rightarrow T^{c}$ & & $1(7.69)$ & 1 \\
\hline \multirow[t]{7}{*}{ ofloxacin } & \multirow[t]{7}{*}{ gyrA } & $C(269) \rightarrow T$ & $\mathrm{Ala}(90) \rightarrow \mathrm{Val}$ & $5(14.29)$ & 4 \\
\hline & & $C(269) \rightarrow G$ & $\mathrm{Ala}(90) \rightarrow$ Gly & $2(5.72)$ & 1 \\
\hline & & $\mathrm{T}(271) \rightarrow C$ & $\operatorname{Ser}(91) \rightarrow$ Pro & $4(11.43)$ & 4 \\
\hline & & $\mathrm{G}(280) \rightarrow \mathrm{T}$ & Asp(94) $\rightarrow$ Tyr & $4(11.43)$ & 3 \\
\hline & & $\mathrm{G}(280) \rightarrow \mathrm{A}$ & Asp(94) $\rightarrow$ Asn & $5(14.29)$ & 4 \\
\hline & & $\mathrm{A}(281) \rightarrow \mathrm{G}$ & Asp(94) $\rightarrow$ Gly & 12(34.29) & 12 \\
\hline & & $A(281) \rightarrow C$ & Asp(94) $\rightarrow$ Ala & $3(8.57)$ & 3 \\
\hline
\end{tabular}

${ }^{\mathrm{a}}$ For rpoB gene, $\mathrm{E}$ coli codon numbering system is used

b, cthese mutations were not found in the TB Drug Resistance Mutation Database (https://tbdreamdb.ki.se/Info/)

there may exist mutations in other loci such as $a h p C$ gene [22]. 47.06\% (24/51) MDR-TB patients were pre$\mathrm{XDR}-\mathrm{TB}$, which was much higher than that of the study by Zhao $\mathrm{Y}$ et al. [2]. The reason might be related to the source of our patients. Our hospital is a specialized hospital for pulmonary diseases. The patients mainly came from the different areas of Hubei province, suffered from severe TB and were treated repeatedly. The result of this study is in agreement with that of previous hospitalbased studies [6, 7].

Mutations in a defined region of the 81 base pair (bp) region of the rpoB gene account for more than 95\% of RIF resistance. Our results showed mutations at positions 531, 526 and 516 were among the most frequent mutations in RIF-resistant strains, which is in agreement with previous studies [23, 24]. Two Mycobacterium

Table 3 Performance of direct sequencing in detecting of resistance of three antitubercular drugs

\begin{tabular}{|c|c|c|c|c|c|c|}
\hline \multirow[t]{2}{*}{ Drugs } & \multirow[t]{2}{*}{ Gene targets } & \multicolumn{3}{|c|}{ No.(\%) of strains/total no. of strains } & \multirow{2}{*}{$\begin{array}{l}\% \\
\text { sensitivity }\end{array}$} & \multirow{2}{*}{$\begin{array}{l}\text { \% } \\
\text { specificity }\end{array}$} \\
\hline & & Phenotypically resistant & $\begin{array}{l}\text { Phenotypically resistant } \\
\text { with mutations }\end{array}$ & $\begin{array}{l}\text { Phenotypically susceptible } \\
\text { with mutations }\end{array}$ & & \\
\hline rifampicin & $r p o B$ & $65 / 186(34.95)$ & 63/65(96.92) & $2 / 121(1.65)$ & 96.92 & 98.35 \\
\hline isoniazid & katG, inhA promoter & $61 / 186(32.80)$ & $53 / 61(86.89)$ & $1 / 125(0.80)$ & 86.89 & 99.20 \\
\hline ofloxacin & gyrA & $40 / 186(21.51)$ & $31 / 40(77.50)$ & $4 / 146(2.74)$ & 77.50 & 97.26 \\
\hline
\end{tabular}


tuberculosis strains had deletion mutations. Four had mutation in codon 533, which were resistant to RIF. Although whether mutation in codon 533 is related to RIF resistance or not is disputed $[8,25,26]$, our results indicated that mutation in codon 533 might cause RIF resistance. In RIF assay, the sensitivity and specificity of the direct sequencing were 96.92 and $98.35 \%$, respectively. We could not detect mutation in 2 phenotypically RIFresistant strains by this study, which could be due to the occurrence of mutations outside the RRDR or other loci in the genome. Direct sequencing detected mutations in 2 specimens that were determined to be phenotypically susceptible. The mutation of one specimen was detected at codon Asp 516 Tyr, the other at codon His 526 Asn. Reportedly, specific mutations in codons 511, 516, 518 and 522 are associated with lower-level resistance to RIF [27].

The katG S315 T mutation is the most common mutation in INH-resistant strains. Resistance to INH can also occur by mutations in the promoter region of mabA/inh $A$ operon, causing overexpression of $i n h A$, or by mutations at the $i n h A$ active site, lowering the $i n h A$ affinity to the INHNAD adduct. Mutations in inhA or its promoter region are usually associated with low-level resistance and are less frequent than $k a t G$ mutations [28]. Our results showed that $k a t G$ gene mutation is the main mutation in INH-resistant strains, followed by inhA promoter. Combination of katG gene with $i n h A$ promoter increased the INH resistance detection by $16.67 \%$ than only detection of $k a t G$ gene. This is in agreement with the report by Seifert M [29]. We found that the katG S315 $\mathrm{T}$ mutation from two retreat patients was heteroresistant by Sanger sequencing plot, this indicated that heteroresistance might develop during repeated treatment. In INH assay, the sensitivity and specificity of the direct sequencing were 86.89 and $99.20 \%$, respectively. There may be mutations in other loci such as $a h p C$ gene [22].

In the present study, gyrA mutations were predominantly found to occur in codons 90, 91, and 94. D94G and $\mathrm{A} 90 \mathrm{~V}$ were the most common mutations, largely corroborating the findings of our previous study [30] and some other studies [31-33]. In OFX assay, the sensitivity and specificity of the direct sequencing were 77.50 and $97.26 \%$, respectively. In the OFX-resistant MTB clinical isolates, 31 of $40(77.50 \%)$ had mutations in quinolone resistance-determining region (QRDR) of gyrA gene and the other nine strains had no mutations in gyrA. Sequencing gyrB gene, especially in MDR-TB patients, increased the sensitivity for FQ resistance by $12 \%$ [34]. Other resistance mechanisms, such as decreased cellwall permeability to the drug and efflux pumps probably accounted for the FQ resistance in other FQ-resistant isolates without gyrA and gyrB mutations [35]. Further studies are needed to improve the sensitivity for FQ resistance. The total mutation frequency of gyrA gene in this study was similar to that in Guangdong province (73.3\%) [36] and that in France (78\%) [34]. Although the total sensitivity of OFX resistance was low (77.50\%), we found that the detection rate of pre-XDR-TB by direct sequencing were $83.33 \%$ (20/24), this would help adjust the treatment regimen for those pre-XDR-TB patients.

There are some limitations in our study. Direct sequencing was mainly applied to smear-positive specimens. There were not enough amplification templates for direct sequencing when smear-negative specimens were used. We amplified different concentrations of $\mathrm{H} 37 \mathrm{Rv}$ strain, more than $10^{4}$ copies $/ \mathrm{ml}$ could be amplified and used for direct sequencing. Smear-positive NTM specimens were not amplified, amplification of IS6110 might be needed to distinguish MTB from NTM.

\section{Conclusions}

In conclusion, direct sequencing is an efficient and accurate method for detecting MDR/pre-XDR-TB from smear-positive sputum specimens. Although there is room to improve the sensitivity of the assay, our results indicate that direct sequencing should be considered a supplemental method for obtaining early DST results before the availability of phenotypic DST results. This could be of benefit to early diagnosis, adjusting the treatment regimen and controlling transmission of drug-resistant $\mathrm{TB}$.

\section{Abbreviations \\ ahpC: Alkyl hydroperoxide reductase gene; FQ: Fluoroquinolone; gyrA: Gyrase A subunit gene; INH: Isoniazid; inhA: NADH-dependent enoyl-ACP reductase gene; katG: Mycobacterial catalase-peroxidase gene; MDR-TB: Multidrug resistant tuberculosis; OFX: Ofloxacin; pre-XDR-TB: Pre-extensively drug-resistant tuberculosis; RIF: Rifampicin; rpoB: the $\beta$ subunit of RNA polymerase gene; TB: Tuberculosis; XDR-TB: Extensively drug-resistant tuberculosis}

\section{Acknowledgements}

We thank the staff of Department of Laboratory medicine, Wuhan Pulmonary Hospital for their support. We appreciated the great assistance of Dr. Ruihua Zhao, from Department of science and technology, Fudan University.

\section{Funding}

This work was supported by China TB Control Program of Global Fund (CHN-S10-G14-T), The Science and Technology Program Of The Health and Family Planning Commission of Wuhan Municipality (WX13B22), The Program of Wuhan Municipal Science and Technology Bureau(201406280101265).

\section{Availability of data and materials}

The datasets supporting the conclusion of this article have been included within the article.

Authors' contributions

WHW, JC, PP and YXD were the primary researchers, conceived and designed the study. JC,PP, YR, LFC and YYR performed DST, identifications, amplification and sequencing, interpreted results and helped draft the manuscript. JC and YXD performed the statistical analysis. JC, PP and WHW wrote the manuscript. All authors read and approved the final manuscript.

\section{Competing interests}

The authors declare that they have no competing interests. 


\section{Ethics approval and consent to participate}

The study was approved by the Medicine Ethics Committee of Wuhan Pulmonary Hospital. The informed consent was obtained from all the patients who were treated in accordance with the Helsinki Declaration on the participation of human subjects in medical research.

\section{Publisher's Note}

Springer Nature remains neutral with regard to jurisdictional claims in published maps and institutional affiliations.

\section{Author details}

'Department of Laboratory Medicine, Wuhan Institute for Tuberculosis Control, Wuhan Pulmonary Hospital, Wuhan 430030, China. ${ }^{2}$ Department of Internal Medicine, Wuhan Institute for Tuberculosis Control, Wuhan Pulmonary Hospital, Wuhan 430030, China. ${ }^{3}$ Department of Tuberculosis Control, Wuhan Institute for Tuberculosis Control, Wuhan Pulmonary Hospital, Wuhan 430030, China.

Received: 4 April 2016 Accepted: 19 April 2017

Published online: 24 April 2017

\section{References}

1. World Health Organization. Global tuberculosis report 2015. 20th edn. Geneva: World Health Organization; 2015.

2. Zhao Y, Xu S, Wang L, Chin DP, Wang S, Jiang G, Xia H, Zhou Y, Li Q, Ou X, et al. National survey of drug-resistant tuberculosis in China. N Engl J Med. 2012;366(23):2161-70.

3. Malik S, Willby M, Sikes D, Tsodikov OV, Posey JE. New insights into fluoroquinolone resistance in Mycobacterium tuberculosis: functional genetic analysis of gyrA and gyrB mutations. Plos One. 2012;7(6):e39754.

4. Smith SE, Ershova J, Vlasova N, Nikishova E, Tarasova I, Eliseev P, Maryandyshev AO, Shemyakin IG, Kurbatova E, Cegielski JP. Risk factors for acquisition of drug resistance during multidrug-resistant tuberculosis treatment, Arkhangelsk oblast, Russia, 2005-2010. Emerg Infect Dis. 2015;21(6):1002-11.

5. Selvakumar N, Kumar V, Balaji S, Prabuseenivasan S, Radhakrishnan R, Sekar G, Chandrasekaran V, Kannan T, Thomas A, Arunagiri S, et al. High rates of ofloxacin resistance in Mycobacterium tuberculosis among both new and previously treated patients in Tamil Nadu, South India. Plos One. 2015;10(3):e0117421.

6. Wang H, Zhang X, Luo T, Li X, Tian P, Xu Y, Gao Q. Prediction of XDR/ pre-XDR tuberculosis by genetic mutations among MDR cases from a hospital in Shandong, China. Tuberculosis. 2014:94(3):277-81.

7. Tang S, Zhang Q, Yu J, Liu Y, Sha W, Sun H, Fan L, Gu J, Hao X, Yao L, et al. Extensively drug-resistant tuberculosis, China. Emerg Infect Dis. 2011; 17(3):558-60.

8. Hillemann D, Rusch-Gerdes S, Richter E. Evaluation of the GenoType MTBDRplus assay for rifampin and isoniazid susceptibility testing of Mycobacterium tuberculosis strains and clinical specimens. J Clin Microbiol. 2007;45(8):2635-40.

9. Shimizu Y, Dobashi K, Yoshikawa Y, Yabe S, Higuchi S, Koike Y, Mita Y, Utsugi M, Endou K, Takahashi K, et al. Five-antituberculosis drug-resistance genes detection using Array system. J Clin Biochem Nutr. 2008;42(3):228-34

10. Helb D, Jones M, Story E, Boehme C, Wallace E, Ho K, Kop J, Owens MR, Rodgers R, Banada P, et al. Rapid detection of Mycobacterium tuberculosis and rifampin resistance by use of on-demand, near-patient technology. J Clin Microbiol. 2010;48(1):229-37.

11. Williamson DA, Basu I, Bower J, Freeman JT, Henderson G, Roberts SA. An evaluation of the Xpert MTB/RIF assay and detection of false-positive rifampicin resistance in Mycobacterium tuberculosis. Diagn Microbiol Infect Dis. 2012;74(2):207-9.

12. Ocheretina O, Escuyer VE, Mabou MM, Royal-Mardi G, Collins S, Vilbrun SC, Pape JW, Fitzgerald DW. Correlation between genotypic and phenotypic testing for resistance to rifampin in Mycobacterium tuberculosis clinical isolates in Haiti: investigation of cases with discrepant susceptibility results. Plos One. 2014;9(3):e90569

13. Rahman A, Sahrin M, Afrin S, Earley K, Ahmed S, Rahman SM, Banu S. Comparison of Xpert MTB/RIF assay and GenoType MTBDRplus DNA probes for detection of mutations associated with Rifampicin resistance in Mycobacterium tuberculosis. Plos One. 2016;11(4):e0152694.
14. Somoskovi A, Dormandy J, Mitsani D, Rivenburg J, Salfinger M. Use of smear-positive samples to assess the PCR-based genotype MTBDR assay for rapid, direct detection of the Mycobacterium tuberculosis complex as well as its resistance to isoniazid and rifampin. J Clin Microbiol. 2006: 44(12):4459-63.

15. Ye J, Coulouris G, Zaretskaya I, Cutcutache I, Rozen S, Madden TL. Primer-BLAST: a tool to design target-specific primers for polymerase chain reaction. BMC Bioinformatics. 2012;13:134

16. Sandgren A, Strong M, Muthukrishnan P, Weiner BK, Church GM, Murray MB Tuberculosis drug resistance mutation database. Plos One. 2009;6(2):e2.

17. Lin SY, Rodwell TC, Victor TC, Rider EC, Pham L, Catanzaro A, Desmond EP. Pyrosequencing for rapid detection of extensively drug-resistant Mycobacterium tuberculosis in clinical isolates and clinical specimens. J Clin Microbiol. 2014;52(2):475-82.

18. Zakham F, Chaoui I, Echchaoui AH, Chetioui F, Elmessaoudi MD, Ennaji MM, Abid M, Mzibri ME. Direct sequencing for rapid detection of multidrug resistant Mycobacterium tuberculosis strains in Morocco. Infect Drug Resist. 2013;6:207-13

19. Zheng R, Zhu C, Guo O, Oin L, Wang J, Lu J, Cui H, Cui Z, Ge B, Liu J, et al. Pyrosequencing for rapid detection of tuberculosis resistance in clinical isolates and sputum samples from re-treatment pulmonary tuberculosis patients. BMC Infect Dis. 2014;14:200.

20. Phelan J, Coll F, McNerney R, Ascher DB, Pires DE, Furnham N, Coeck N, Hill-Cawthorne GA, Nair MB, Mallard K, et al. Mycobacterium tuberculosis whole genome sequencing and protein structure modelling provides insights into anti-tuberculosis drug resistance. BMC Med. 2016;14:31.

21. Luo T, Zhao M, Li X, Xu P, Gui X, Pickerill S, DeRiemer K, Mei J, Gao Q. Selection of mutations to detect multidrug-resistant Mycobacterium tuberculosis strains in Shanghai, China. Antimicrob Agents Chemother. 2010:54(3):1075-81.

22. Kiepiela P, Bishop KS, Smith AN, Roux L, York DF. Genomic mutations in the katG, inhA and ahpC genes are useful for the prediction of isoniazid resistance in Mycobacterium tuberculosis isolates from Kwazulu Natal, South Africa. Tuber Lung Dis. 2000:80(1):47-56.

23. Ajbani K, Lin SY, Rodrigues C, Nguyen D, Arroyo F, Kaping J, Jackson L, Garfein RS, Catanzaro D, Eisenach K, et al. Evaluation of pyrosequencing for detecting extensively drug-resistant Mycobacterium tuberculosis among clinical isolates from four high-burden countries. Antimicrob Agents Chemother. 2015;59(1):414-20.

24. Campbell PJ, Morlock GP, Sikes RD, Dalton TL, Metchock B, Starks AM, Hooks DP, Cowan LS, Plikaytis BB, Posey JE. Molecular detection of mutations associated with first- and second-line drug resistance compared with conventional drug susceptibility testing of Mycobacterium tuberculosis. Antimicrob Agents Chemother. 2011;55(5):2032-41.

25. Ma X, Wang H, Deng Y, Liu Z, Xu Y, Pan X, Musser JM, Graviss EA. rpoB Gene mutations and molecular characterization of rifampin-resistant Mycobacterium tuberculosis isolates from Shandong Province, China. J Clin Microbiol. 2006;44(9):3409-12.

26. Yue J, Shi W, Xie J, Li Y, Zeng E, Wang H. Mutations in the rpoB gene of multidrug-resistant Mycobacterium tuberculosis isolates from China. J Clin Microbiol. 2003:41(5):2209-12.

27. Feuerriegel S, Oberhauser B, George AG, Dafae F, Richter E, Rusch-Gerdes S, Niemann S. Sequence analysis for detection of first-line drug resistance in Mycobacterium tuberculosis strains from a high-incidence setting. BMC Microbiol. 2012;12:90.

28. Hazbon MH, Brimacombe M, Bobadilla del Valle M, Cavatore M, Guerrero MI, Varma-Basil M, Billman-Jacobe H, Lavender C, Fyfe J, Garcia-Garcia L, et al. Population genetics study of isoniazid resistance mutations and evolution of multidrug-resistant Mycobacterium tuberculosis. Antimicrob Agents Chemother. 2006:50(8):2640-9.

29. Seifert M, Catanzaro D, Catanzaro A, Rodwell TC. Genetic mutations associated with isoniazid resistance in Mycobacterium tuberculosis: a systematic review. Plos One. 2015;10(3):e0119628.

30. Chen J, Chen Z, Li Y, Xia W, Chen X, Chen T, Zhou L, Xu B, Xu S. Characterization of gyr $A$ and gyrB mutations and fluoroquinolone resistance in Mycobacterium tuberculosis clinical isolates from Hubei Province, China Braz J Infect Dis. 2012;16(2):136-41.

31. Von Groll A, Martin A, Jureen P, Hoffner S, Vandamme P, Portaels F, Palomino JC, da Silva PA. Fluoroquinolone resistance in Mycobacterium tuberculosis and mutations in gyrA and gyrB. Antimicrob Agents Chemother. 2009:53(10):4498-500. 
32. Mokrousov I, Otten T, Manicheva O, Potapova Y, Vishnevsky B, Narvskaya O, Rastogi N. Molecular characterization of ofloxacin-resistant Mycobacterium tuberculosis strains from Russia. Antimicrob Agents Chemother. 2008:52(8):2937-9.

33. Avalos E, Catanzaro D, Catanzaro A, Ganiats T, Brodine S, Alcaraz J, Rodwell T. Frequency and geographic distribution of gyrA and gyrB mutations associated with fluoroquinolone resistance in clinical Mycobacterium tuberculosis isolates: a systematic review. Plos One. 2015;10(3):e0120470.

34. Bernard C, Veziris N, Brossier F, Sougakoff W, Jarlier V, Robert J, Aubry A. Molecular diagnosis of fluoroquinolone resistance in Mycobacterium tuberculosis. Antimicrob Agents Chemother. 2015;59(3):1519-24.

35. Escribano I, Rodriguez JC, Llorca B, Garcia-Pachon E, Ruiz M, Royo G. Importance of the efflux pump systems in the resistance of Mycobacterium tuberculosis to fluoroquinolones and linezolid. Chemotherapy. 2007;53(6):397-401.

36. Yin $X$, Yu Z. Mutation characterization of gyrA and gyrB genes in levofloxacin-resistant Mycobacterium tuberculosis clinical isolates from Guangdong Province in China. J Infect. 2010;61(2):150-4.

Submit your next manuscript to BioMed Central and we will help you at every step:

- We accept pre-submission inquiries

- Our selector tool helps you to find the most relevant journal

- We provide round the clock customer support

- Convenient online submission

- Thorough peer review

- Inclusion in PubMed and all major indexing services

- Maximum visibility for your research

Submit your manuscript at www.biomedcentral.com/submit
C) Biomed Central 